University of Nebraska - Lincoln

DigitalCommons@University of Nebraska - Lincoln

USDA Wildlife Services - Staff Publications

U.S. Department of Agriculture: Animal and Plant Health Inspection Service

2017

\title{
Attractants for wild pigs: current use, availability, needs, and future potential
}

\author{
Michael J. Lavelle \\ USDA/APHIS/WS National Wildlife Research Center, michael.j.lavelle@aphis.usda.gov \\ Nathan P. Snow \\ USDA/APHIS/WS National Wildlife Research Center, nathan.p.snow@aphis.usda.gov \\ Justin W. Fischer \\ USDA/APHIS/WS National Wildlife Research Center, Justin.w.fischer@aphis.usda.gov \\ Joe M. Halseth \\ USDA APHIS Wildlife Services \\ Eric H. VanNatta \\ USDA APHIS Wildlife Services
}

See next page for additional authors

Follow this and additional works at: https://digitalcommons.unl.edu/icwdm_usdanwrc

Part of the Life Sciences Commons

Lavelle, Michael J.; Snow, Nathan P.; Fischer, Justin W.; Halseth, Joe M.; VanNatta, Eric H.; and VerCauteren, Kurt C., "Attractants for wild pigs: current use, availability, needs, and future potential" (2017). USDA Wildlife Services - Staff Publications. 2028.

https://digitalcommons.unl.edu/icwdm_usdanwrc/2028

This Article is brought to you for free and open access by the U.S. Department of Agriculture: Animal and Plant Health Inspection Service at DigitalCommons@University of Nebraska - Lincoln. It has been accepted for inclusion in USDA Wildlife Services - Staff Publications by an authorized administrator of DigitalCommons@University of Nebraska - Lincoln. 
Authors

Michael J. Lavelle, Nathan P. Snow, Justin W. Fischer, Joe M. Halseth, Eric H. VanNatta, and Kurt C. VerCauteren 


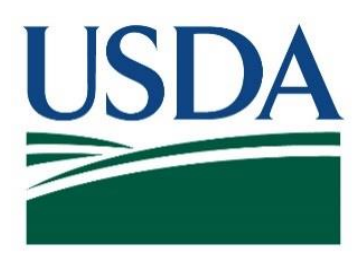

U.S. Department of Agriculture

U.S. Government Publication

Animal and Plant Health Inspection Service

Wildlife Services

Lavelle, M. J., N. P. Snow, J. W. Fischer, J. M. Halseth, E. H. VanNatta, and K. C. VerCauteren. 2017. Attractants for wild pigs: current use, availability, needs, and future potential.

European Journal of Wildlife Research 63:86 


\title{
Attractants for wild pigs: current use, availability, needs, and future potential
}

\author{
Michael J. Lavelle $^{1}$ (D) Nathan P. Snow ${ }^{1} \cdot$ Justin W. Fischer $^{1} \cdot$ Joe M. Halseth $^{1}$ • \\ Eric H. VanNatta ${ }^{1} \cdot$ Kurt C. VerCauteren $^{1}$
}

Received: 5 June 2017 / Revised: 3 October 2017 / Accepted: 9 October 2017

(C) US Government (outside the USA) 2017

\begin{abstract}
Populations of wild pigs (Sus scrofa) are burgeoning around the globe, and they are currently the target of extensive research and management efforts. Wild pigs are a highly successful invasive species that cause extensive damage to agriculture and native plant and animal communities. Lethal control is the most common management strategy used to reduce wild pig populations and their damage, and many lethal strategies rely on luring wild pigs to a specific location. Most commonly, a food commodity such as corn or maize (Zea mays) is used for attracting wild pigs to a site, but baiting with food is sometimes prohibited under wildlife laws, and visitation can be variable due to availability of alternative foods, level of harassment by humans, and acceptance of novel food source, devices, and activity. Wild pigs are highly adaptable with refined senses that enable them to interact with their environment and conspecifics in a complex manner. Wild and domestic pigs share keen senses, though differences exist due to suppressed stimuli, evolutionary gains and losses, or other factors related to needs for survival and fitness. Wild pigs routinely rely on acute olfaction to locate food, detect predators, and communicate with conspecifics. A pig's sense of taste is also considered to be refined and more acute than that of humans. An abundance of evaluations regarding various attractants for wild pigs has been conducted over the last
\end{abstract}

Electronic supplementary material The online version of this article (https://doi.org/10.1007/s10344-017-1144-z) contains supplementary material, which is available to authorized users.

Michael J. Lavelle

michael.j.lavelle@aphis.usda.gov

1 United States Department of Agriculture, Animal and Plant Health Inspection Service, Wildlife Services, National Wildlife Research Center, 4101 LaPorte Avenue, Fort Collins, CO 80521-2154, USA several decades; yet, a scarcity of conclusive results on which attractants to use when and where still exists. As such, we undertook a comprehensive review of available information on potential attractants that could be used to aid management strategies of wild pigs such as hunting/shooting, trapping, pharmaceutical delivery, or density estimation. To complete this review, we assimilated and synthesized the most relevant literature, provide recommendations, and identify attractant evaluation needs for the enhancement of the global management of wild pigs.

Keywords Attractant · Bait · Wild pigs · Lure · Sus scrofa

\section{Introduction}

The success of most tools in the wildlife management toolbox is dependent upon behavioral responses of the target species. Wild pigs (Sus scrofa), also known as feral swine, feral pigs, and wild boar, occur around the world with between 14 to 23 recognized "subspecies," including both native and nonnative invasive populations (Mayer and Brisbin 2009). Wild pigs are an ever-increasing recipient of wildlife management actions, especially in areas where they cause damage or pose risk to human health and safety (Mayer and Brisbin 2009). For example, wild boar in Spain are a reservoir host for bovine tuberculosis and maintain the threat of infection to livestock and wildlife (Gortázar et al. 2008). Across their worldwide range, wild pigs negatively impact resources as exemplified by damage they cause to cultivated corn or maize (Zea mays) in Iberia (Herrero et al. 2006), vineyards in France (Calenge et al. 2004), rice (Oryza sativa) paddies in Japan (Saito et al. 2011), sea bird nesting on Auckland Island (Challies 1975), and native ecosystems in Hawaii (Cuddihy and Stone 1990). As the range of wild pigs expands, along with development of 
lands for human uses, human-wild pig conflicts will escalate, emphasizing the need for improved management options (Saito et al. 2012; Snow et al. 2016a).

Wild pigs have been introduced into numerous countries with substantial populations in the USA and Australia (AU) (Spencer and Hampton 2005; Snow et al. 2016a). Populations continue to expand due to their adaptability and high reproductive potential as well as intentional translocations and releases (Bevins et al. 2014). As such, wild pigs are the most abundant introduced ungulate globally (Sweeney et al. 2003). The damage wild pigs cause to natural and agricultural resources is extensive (Seward et al. 2004; Anderson et al. 2016). For example, economists conservatively estimated agricultural damage caused by wild pigs in the USA to be $\$ 800$ million/year or $\$ 200 /$ animal/year (Pimentel et al. 2005). The state of Texas, USA, alone reported having more than two million wild pigs, suggesting a financial burden of $\$ 400$ million/year which must be absorbed by agricultural producers (Mapston 2007). Given the precipitous increase in abundance and distribution of wild pigs and subsequent rise in human conflicts (Dickson et al. 2001; Adams 2016), it is apparent that current control efforts have not been universally successful. More effective methods to control wild pig damage or improvements to existing strategies are needed (Sweeney et al. 2003).

Most management strategies used for estimating densities, capturing, and removing wild pigs, or for delivering baits containing pharmaceuticals rely on attractants to stimulate and maintain visitation to a location where a management action can then be implemented. Recognizing that wildlife trapping or hunting nomenclature may differ across countries and within countries at state and federal levels, here we use the term "attractants" to broadly encompass anything that entices animals to a specific location regardless of the sense(s) targeted. We use the term "baiting" to describe the act of deploying an attractant in the field with the goal of drawing animals to a particular location. For our purposes, food attractants or "bait" include any items that elicit feeding or licking behavior, auditory attractants include manual and electronic calls, visual attractants include objects or decoys, and scent attractants encompass items that give off olfactory clues (Table 1). In reality, some attractants target more than one sense and may fall into several categories. For instance, scent attractants, such as commercially available liquid additives and enhancers, can also overlap food resources that target taste such as soured corn (Fig. 1). In areas where corn is commonly used to attract game, it can be a visual attractant and it has scent and auditory attractant properties such as when broadcast from a spin-cast feeder.

Wild pigs often respond predictably to attractants; however, there will undoubtedly be variability in responses among individuals, exacerbating management challenges (Saunders and Bryant 1988). Despite high levels of curiosity in domestic pigs (Wood-Gush and Vestergaard 1991; Kittawornrat and Zimmerman 2011), wild pigs are highly sensitive to changes in their environment and often alter their behaviors in response to new objects (Muir and McEwen 2007; Campbell et al. 2010). Additionally, commonly used attractants (e.g., corn) oftentimes appeal to non-target species resulting in increased costs and missed opportunity (e.g., tripped traps). Species specificity of attractants is a requisite for minimizing potential delivery of pharmaceuticals to non-target species, minimizing non-target captures, and reducing consumption by non-target species (Fleming et al. 2000; Kavanaugh and Linhart 2000; Campbell and Long 2007; Campbell and Long 2008). Therefore, identification of attractants that appeal more

Table 1 Mode of action of various types of attractants used for drawing in and concentrating wild pigs (Sus scrofa) including specifically targeted physiological senses, motivation for visitation, pros and cons of use, and examples of each

\begin{tabular}{|c|c|c|c|c|c|}
\hline $\begin{array}{l}\text { Attractant } \\
\text { type }\end{array}$ & Targeted sense & Motivation & Pros & Cons & Examples \\
\hline Food & Gustation/olfaction & Consumption & $\begin{array}{l}\text {-Often preferred over natural foods } \\
\text {-Can be odorous resulting in high } \\
\text { rate of attraction }\end{array}$ & $\begin{array}{l}\text {-Legal restrictions of bait use vary } \\
\text { among locations } \\
\text {-Lack species specificity } \\
\text {-Effectiveness based on seasonal } \\
\text { availability of natural food sources } \\
\text { and agriculture crops }\end{array}$ & $\begin{array}{l}\text { Corn, wheat, } \\
\text { rotten fruit }\end{array}$ \\
\hline Scent & Olfaction/gustation & $\begin{array}{l}\text { Breeding, } \\
\text { communicatio- } \\
\mathrm{n} \text {, or } \\
\text { consumption }\end{array}$ & $\begin{array}{l}\text {-Increased species specificity } \\
\text {-Targets strongest sense, effective } \\
\text { in attracting for food and/or } \\
\text { conspecific motives }\end{array}$ & $\begin{array}{l}\text {-Dissipates, thus necessitating } \\
\text { reapplication } \\
\text {-Lacks consumable or conspecific } \\
\text { "reward" }\end{array}$ & $\begin{array}{l}\text { Sow in estrus, } \\
\text { boar taint, } \\
\text { strawberry } \\
\text { scent }\end{array}$ \\
\hline Calls/auditory & Audition & $\begin{array}{l}\text { Breeding, } \\
\text { communicatio- } \\
\mathrm{n} \text {, or } \\
\text { consumption }\end{array}$ & -Increased species specificity & $\begin{array}{l}\text {-Efficacy unknown } \\
\text {-Limited range of attraction } \\
\text {-Lacks conspecific "reward" }\end{array}$ & $\begin{array}{l}\text { Recorded pig } \\
\text { sounds }\end{array}$ \\
\hline Decoys/visual & Vision & $\begin{array}{l}\text { Breeding or } \\
\text { communication }\end{array}$ & -Increased species specificity & -Dependent on visibility & $\begin{array}{l}\text { Sow or boar } \\
\text { decoy }\end{array}$ \\
\hline
\end{tabular}


Fig. 1 Examples of unique baiting strategies to improve success in increasing visitation and capture rates of wild pigs (Sus scrofa) including a a "corn hole" which is a small-diameter hole $(\approx 25 \mathrm{~cm}$ in circumference and $\approx 35 \mathrm{~cm}$ depth) dug in the ground and filled with attractants (photo credit NWRC); $\mathbf{b}$ fermented or soured corn which is highly odorous (photo credit $\mathrm{C}$. Thomas, USDA WS); and $\mathbf{c}$ a hog pipe which is a capped PVC pipe with holes drilled in it that corn or other grain-based commodities are gradually dispensed from as it is manipulated by wild pigs (photo credit NWRC)

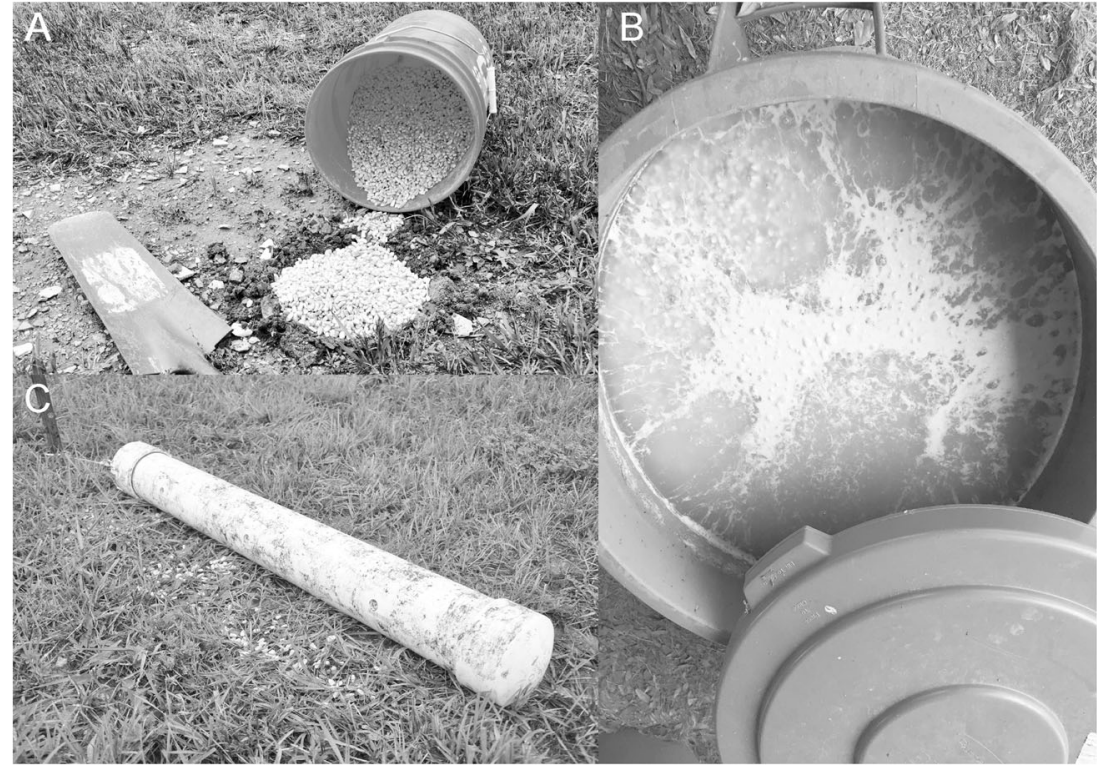

specifically to wild pigs is needed. A current challenge in targeting wild pigs is that many countries have restrictions on use of food attractants or bait. For example, 15 of 42 states in the USA with wild pigs have restrictions on use of food attractants or bait, usually associated with timing of hunting seasons for native game species. Further, many states restrict use of attractants to private lands only or limit the amount or type of attractant used. As such, identifying a suite of different types of effective attractants would aid in management of wild pigs in areas that limit use of bait or do not allow year-round baiting.

Objectives In order to concentrate wild pigs at a location and maintain routine visitation, an enticing or preferred substance(s) must be dispersed. As generalist foragers, wild pigs will respond to an array of dissimilar attractants; yet, grains such as wheat (Triticum aestivum) and corn seem to be widely accepted and reliably consumed. Due to common attractant challenges such as competition with natural forage, non-target species bait consumption, and legal restrictions, a clear and comprehensive review of existing literature leading to recommended alternatives for enticing wild pigs was the primary goal of this manuscript. The first section focuses on food habits of wild pigs with forage resources being a primary driver of everyday activity. Second is a section on socially related factors that influence habits of wild pigs. The third section provides an overview of the physiological senses (taste, smell, sight, and hearing) of wild pigs and how they relate to attractants. The remainder of this review summarizes research results, anecdotal reports, and commercially available products targeting the different senses of wild pigs. Our final goal was to suggest next steps in research of attractants for wild pigs. As such, all substances that attract wild pigs need to be considered to help identify effective options when a particular attractant is ineffective or not allowed.

\section{Food as motivation}

Wild pigs are omnivorous, generalist, and opportunistic feeders (Sweeney et al. 2003). Therefore, the list of naturally occurring items that wild pigs eat is vast, and varies by region and season. A detailed list of food habits and items consumed are provided by Ditchkoff and Mayer (2009). Although wild pigs can survive on nearly anything consumable, the tendency of wild pigs to maximize consumption of preferred foods during peak seasons of availability represents an exploitable behavior for attraction. With this concept in mind, we provide a general overview of wild pig food habits.

As foragers, wild pigs seek easily digestible vegetation that is low in structural carbohydrates and high in simple sugars, starches, and lipids such as fruits, seeds, bulbs, tubers, and roots (Ditchkoff and Mayer 2009; Mayer and Brisbin 2009). While vegetation typically makes up the majority of a pig's diet, there are slight variations in preferences. For example, adult males typically consume more carrion and animal matter than other sexes and age classes, and younger pigs often consume a wider array of foodstuffs than other age classes (Mayer and Brisbin 2009).

During wet seasons, wild pigs are primarily grazers focusing on the soft mast of sprouting grasses and herbs (Wood and Barrett 1979; Taylor and Hellgren 1997) and fungi (Ditchkoff and Mayer 2009). During later seasons, hard mast crops such as acorns (Quercus spp.), beechnuts (Fagus spp.), chestnuts (Castanea spp.), and hickory nuts (Carya spp.) are preferred (Henry and Conley 1972; Sweitzer and Van Vuren 2002; 
Sweeney et al. 2003). Other seasonally available fruits, seeds, and emerging sprouts are also intensely consumed by wild pigs (Ditchkoff and Mayer 2009). When easily obtained or more preferred foods are not available, alternative foods such as rhizomes, tubers, fleshy roots, and macroinvertebrates are acquired via subterranean rooting (Singer 1981; Thomson and Challies 1988; Taylor and Hellgren 1997; Ditchkoff and Mayer 2009).

Agricultural plants are consumed in equal or higher proportion than non-agricultural plants, when available (Schley and Roper 2003; Herrero et al. 2006; Giménez-Anaya et al. 2008). Food preferences of wild pigs are reflective of the crops available to them (Schley and Roper 2003). Corn appears to be the most preferred agricultural plant in North America but is often supplied artificially for hunting purposes, and thus may not be representative of typical consumption from agricultural fields (Schley and Roper 2003). Soybeans (Glycine max), peanuts (Arachis hypogaea), and artichokes (Cynara scolymus) are also highly desired during the short season when the plants are mature (Pine and Gerdes 1973; Ditchkoff and Mayer 2009). Wheat, sorghum (Sorghum bicolor), rice, barley (Hordeum vulgare), and other grains are also commonly consumed (Schley and Roper 2003; Herrero et al. 2006; Ditchkoff and Mayer 2009; Ballari and Barrios-García 2014).

Most reports have suggested that wild pigs consume invertebrate and vertebrate tissue primarily on an opportunistic basis (Ditchkoff and Mayer 2009); therefore, these food items are not believed to be actively sought by wild pigs except when locally or seasonally abundant. Additionally, consumption of animal matter may be important for growth and survival of young wild pigs (Schley and Roper 2003). Commonly consumed animal items include birds, small mammals, deer fawns, young wild pigs, herpetofauna, and eggs of ground nesting birds and reptiles (Ruckel and Steele 1984; Schley and Roper 2003; Ditchkoff and Mayer 2009; Elsey et al. 2012; Ballari and Barrios-García 2014). Earthworms (Lumbricus terrestris) and grubs also appear to be preferred and highly sought in some areas (Baubet et al. 2003; HeisePavlov et al. 2005; C. Hicks and R. Jones, USDA APHIS Wildlife Services [WS], personal communication).

Wild pigs need routine access to surface water for drinking and thermoregulation (Baber and Coblentz 1986; Gabor et al. 1997) and subsequently prefer to bed, wallow, and forage near seeps, springs, and lakes (Baber and Coblentz 1986; Atwill et al. 1997). Although wild pigs are mostly nocturnal, activity at waterholes during midday suggests increased need or desire to drink or wallow in response to dry environmental conditions (Graves 1984; Fernández-Llario 2005). Further, increased wallowing by adult male European wild boar coincides with the breeding season suggesting that wallowing may serve territorial or sexual functions as well (Fernández-Llario 2005).

\section{Conspecifics (intraspecific communication) as motivation}

Aside from foraging, other natural behaviors are exploitable for attracting wild pigs. Notably, wild pigs are highly social (Gabor et al. 1999; Mayer 2009), and as such, movements of wild pigs are largely attributed to group behaviors (for females and juveniles) and reproduction (for males). With these behaviors in mind, we provide an overview of the social behaviors of wild pigs.

Females and young wild pigs form social groups (i.e., sounders) averaging three to nine individuals (Mayer 2009). Wild pigs within sounders generally have smaller home ranges and high degrees of overlap among adjacent sounders (Kurz and Marchinton 1972; Janeau and Spitz 1990; Boitani et al. 1994; Caley 1997). Intra-sounder dynamics are highly complex, suggesting that wild pigs evolved as a communal species and therefore seek conspecifics similar to other communal species (Gabor et al. 1999; Witmer et al. 2014). For instance, solo females contacted other resident wild pigs in a nearby area within 1-7 days of release (Mcllroy and Gifford 1997). Similarly, females with young rejoined their sounders only 9 days after farrowing (Jensen 1986).

Adult males are less communal than females, except when participating in breeding behaviors (Mayer 2009). Females are capable of reproducing year-round, but the breeding season in general is typically concentrated to two peaks driven by seasonal food abundance (Comer and Mayer 2009). During these peaks, males seek estrous females for mating opportunities using odor cues. Estrous females are attractive to males for 4-5 days (Mcllroy and Gifford 2005) and come into heat every 18-24 days if not pregnant (Comer and Mayer 2009). Adult males ( $>90 \mathrm{~kg}$ ) may travel long distances $(>30 \mathrm{~km})$ to successfully reproduce (Hampton et al. 2004). Because of this roaming behavior, males can be difficult to locate and capture using traditional, food-based attractants. However, presence of females in estrus in proximity to capture sites may help overcome this difficulty (Choquenot et al. 1993; Mcllroy and Gifford 2005).

\section{Physiological senses driving motivation}

Sense of smell The olfactory system, or sense of smell, of pigs is considered to be their most acute sense (Guntherschulze 1979; Graves 1984; Croney et al. 2003; Kittawornrat and Zimmerman 2011). Olfaction plays a key role in navigation through their environment. Animals use olfactory capabilities to locate chemical signals advertising unique conspecific behaviors such as reproduction and social communication as well as to continuously evaluate their surroundings to identify food sources, danger, and environmental changes (Breer et al. 
2006). A unique physical characteristic of pigs is their enlarged snout which enables them to find and access food items through their rooting behavior. The snout ties into the upper lip and lies at the end of the rostrum, a thinwalled, tubular assemblage of several bones located at the terminal end of the maxilla (Dyce et al. 1987; Rafferty et al. 2003; Kittawornrat and Zimmerman 2011).

Like most mammals, wild pigs use olfactory capabilities to aid in interspecific communication. Young pigs use olfactory cues early in life to recognize maternal odor, teat position in nursing, and recognize individuals (Kittawornrat and Zimmerman 2011). Odiferous glandular secretions are tied to communication and behavior through scent marking, mating, and other complex interspecific relationships (Graves 1984; Dorries et al. 1991; Hraste and Stojković 1995; Heise-Pavlov et al. 2005). Wild pigs possess numerous glands that secrete compounds including preputial, anal, carpal, metacarpal, mandibular, salivary, Harderian, and eyelid (Mykytowycz 1977; Estes et al. 1982). The presence of odiferous secretions, specifically androstenone from salivary glands, has been related to breeding behavior in both wild and domestic pigs (Melrose et al. 1971; Estes et al. 1982; Graves 1984; Dorries et al. 1991). Carpal glands from wild pigs were found to be generally more robust and complex than those of domestic pigs and likely play a role in breeding activity (Hraste and Stojković 1995; Farnesi et al. 1999; Heise-Pavlov et al. 2005; Bacchetta et al. 2007).

The steroid androstenone has long been identified as the classic boar odor that taints domestic pig meat, and numerous studies have looked at ways to eliminate the compound to benefit commercial pork production (Brooks and Pearson 1986). Androstenone is synthesized in testes, transmitted through the blood stream to the submaxillary and salivary glands, and released through saliva upon sexual stimulation (Brooks et al. 1990; Dorries et al. 1995). The odor of this compound is detected by females during estrus, resulting in the characteristic mating stance allowing a male to breed (Melrose et al. 1971; Dorries et al. 1995), and was shown capable of identifying receptive female pigs (Melrose et al. 1971; Reed et al. 1974).

Multiple sensory systems may be used by pigs for communication, in which olfaction could be coupled with visual and/ or auditory stimuli like vocalizations and postures (Meese et al. 1975; Mykytowycz 1977; Corona and Lévy 2015). Using solely olfaction, pigs were able to distinguish urine from conspecifics including urine from intact males, females, castrated males, and young females (Meese et al. 1975). Females use olfaction to recognize their offspring, will reject conspecific young a short time after partition, and are more capable of recognizing their own piglets who have nursed and have had snout-to-snout contact than those that have not (Corona and Lévy 2015).
Sense of taste The gustatory system of pigs is also well developed (Tinti et al. 2000; Roura et al. 2011; Roura et al. 2016). Similar to their extraordinary sense of smell, their sense of taste is thought to be the most developed of all mammals, including humans, due to high numbers of taste buds (Bradley 1971; Chamorro et al. 1993). Taste receptors on taste buds are an important component of the system by coming directly into contact with non-volatile or water-based food items thus initiating the taste sensation (Bachmanov and Beauchamp 2007).

Taste receptors of pigs can differentiate between the five taste sensations of sweet, salty, bitter, sour, and umami (savory) (Bachmanov and Beauchamp 2007; Roura et al. 2008), giving them the ability to differentiate molecules within food items. Sweet and umami taste categories often represent sugars and proteins that are known to trigger gustatory preferences in pigs, while bitter compounds, which may signal rotten or rancid food items, are often rejected (Hellekant and Danilova 1999). It is likely that the sense of taste evolved to aid animals in finding nutritionally beneficial foods while avoiding toxic compounds, as associations have been made between nutritive value of food items and the corresponding taste preference or rejection (Miller and Reedy 1990). The effects of a pig's diet, health, age, and environmental factors may also influence taste preference (McLaughlin et al. 1983; Danilova et al. 1999). Additionally, an individual's genetics may cause additional variation in taste preferences such as taste blindness or particular sensitivity to certain compounds (Bachmanov and Beauchamp 2007; da Silva et al. 2014). Each of these factors contributes to variability in responses when attempting to narrow taste preferences of pigs.

Several studies have investigated taste preferences by monitoring nerve stimulation and have shown particular preferences for sweeteners including xylitol, glycine, and saccharine (Kare et al. 1965; Danilova et al. 1999; Glaser et al. 2000), lugduname and carrelame (Nofre et al. 2002), and the sugars glucose, sucrose, fructose, and lactose, (Kennedy and Baldwin 1972; Hellekant and Danilova 1996; Hellekant and Danilova 1999). Pigs have also shown preference for umami flavors, including monosodium-glutamate (MSG) and similar chemicals, guanosine-5'-monophosphate and inosine-5'monophosphate (Danilova et al. 1999; Hellekant and Danilova 1999). It has also been suggested that adding cheesy, fruity, meaty, and sweet flavors to foodstuffs may increase consumption and palatability by young pigs (McLaughlin et al. 1983; Roura et al. 2011).

Compounds that are often rejected by pigs include tilmicosin (Hellekant and Danilova 1999), caffeine, denatonium benzoate, quinine (Nelson and Sanregret 1997), and other bitter compounds (Tinti et al. 2000). Repellents marketed toward mitigating damage by wild pigs focus on compounds that initiate these aversive reactions, but may have questionable efficacy. For example, an acidic substance intended as a gustatory repellent based on its sour taste was 
shown to be ineffective in deterring wild pigs from crop fields (Schlageter and Haag-Wackernagel 2012).

Food attractants targeting smell and taste Recently, there has been a focus on identifying preferred attractants for wild pigs designed for the delivery of pharmaceuticals or toxicants (Campbell et al. 2006; Campbell and Long 2007; Snow et al. 2016b). Most attractants attempt to exploit the sense of smell, because it is renowned as the most developed sense of wild pigs. Attractants that target the sense of smell do so by targeting and mimicking food resources. In targeting food resources, an effective attractant will stimulate both smell and taste. Wild pigs use their sense of smell to locate the attractant, and the food resource presents a reward for the sense of taste. This reward, ample supply, and/or timely resupply of the attractant increase the probability of repeat visitation by wild pigs to an attractant site. Previous research demonstrated a black-colored peanut paste performed equally as well as whole-kernel corn for eliciting wild pig visitations though it was noticeably more fragrant (Snow et al. 2016b). Further, Campbell et al. (2006) concluded that peanut-based attractants elicited more visitations by wild pigs than raccoons (Procyon lotor) or collared peccaries (Pecari tajacu).

Conspecific attractants targeting smell In targeting conspecifics, scent attractants seek to trigger responses relating to reproductive, territoriality, or aggressive behaviors. Effectiveness of using scent attractants to target wild pig conspecifics is situationally variable. Initial visitation in luring wild pigs to an area using scent attractants targeting conspecifics may be successful; however, consistent repeat visitation using attractants solely targeting conspecifics is less likely to occur than with strategies where a food resource reward is provided. Yet, in areas of low-density wild pig populations, application of domestic pig manure in and around a trap has demonstrated success in drawing wild pigs into a trap (R. Powers, USDA APHIS WS, personal communication). Androstenone, as mentioned above, is available in the commercial products Boarmate ${ }^{\mathrm{TM}}$ (Kerbl GmbH, Buchbach, Germany) and Hog Mate ${ }^{\mathrm{TM}}$ (Reproduction Provisions, LLC, Chicago, IL, USA), both of which are used to identify females in estrus to aid in efficiency of artificial insemination, and to stimulate new or inexperienced breeders (Wathen et al. 1988; Campbell and Long 2008). Pigs have long been used to locate truffles in Europe as truffles exhibit the same enticing chemical pheromone androstenone (Claus et al. 1981; Pacioni 1986; Watson 2004).

Sense of sight The visual capacity of wild pigs is limited and is less acute than their senses of olfaction and hearing. For example, it is believed that domestic pigs have dichromatic color vision and can only discriminate blue from the other primary colors (Neitz and Jacobs 1989; Tanida et al. 1991;
Eguchi et al. 1997). Color discrimination in domestic pigs is stated to be gender driven, with newborn female pigs preferring blue and males preferring red (Deligeorgis et al. 2006). Because of the poor ability of domestic pigs to differentiate colors and distinguish other visual cues, it is unlikely they rely on their sense of vision as much as other sensory faculties when interacting with their environment and conspecifics. Further, it is also unlikely that visual cues alone may be sufficient to draw wild pigs to an area otherwise unvisited.

Sense of hearing The auditory capacity of domestic pigs is similar to that of humans, but with a shift toward ultrasound frequencies (Heffner and Heffner 1990; Kittawornrat and Zimmerman 2011). Domestic pigs also have an acute sound localization threshold, similar to cats and monkeys, when compared to other hoofed mammals (Heffner and Heffner 1990). As well as using auditory stimuli to detect potential predators in their natural surroundings or how they perceive sounds in production environments, domestic pigs have welldeveloped vocal abilities to communicate with conspecifics during daily and social activities. Females and piglets use various vocalizations to initiate nursing (Whittemore and Fraser 1974; Fraser 1980; Algers 1993), males will emit grunts and chomp their jaws during courtship (Graves 1984), and piglets will use open- and closed-mouth grunts and squeals to maintain contact with littermates and their dam (Hutson et al. 1992; Weary and Fraser 1995; Weary et al. 1998).

Attractants targeting sight and hearing Relatively speaking, there is an abundance of research evaluating sensory abilities of wild pigs to taste and smell attractants relative to preferences and dislikes; however, far less is known about how attractants that target both sight and sound affect their behaviors. Many have tested the cognitive ability of domestic pigs to learn and remember particular situations, often including a food reward, but most of the testing paradigms included a combination of visual, auditory, and olfactory cues (for reviews, see Held et al. 2009; Gieling et al. 2011; Kornum and Knudsen 2011). Albeit challenging when trying to identify which sensory cue is most desirable to exploit regarding potential attractants, various strategies have been used to counteract confounding sensory cues (e.g., vinegar/water solution [Kouwenberg et al. 2009]; odor neutralizers [McLeman et al. 2005]), increasing distance and decreasing light levels (Koba and Tanida 2001).

It has been documented that wild pigs will forage on American alligator (Alligator mississippiensis) eggs and new hatchlings (Elsey et al. 2012; Ruckel and Steele 1984). Young alligators produce vocalizations, similar to a grunt, while still in the egg that could elicit a foraging response from wild pigs in the area (Garrick et al. 1978), or this response may be a combination of odor and auditory cues from the alligator nest 
to which wild pigs are attracted. Wild pigs may also use their sense of hearing to detect grubs, beetles, or other invertebrates burrowing below the surface of the soil.

Even though wild pigs are considered opportunistic omnivores, they will draw on previous experiences when interacting with their environment. Wild pigs that have been trained that visual or auditory cues equate to a food reward will shift their behavior to the location of those cues in space and time. An example of this associative learning might be the sound of a game feeder dispensing corn. This unique sound could alert wild pigs in the vicinity to the availability of a new, short-term food resource. The sound of vehicles, car doors slamming, or grain buckets may also spur a similar response in areas where corn is routinely dispersed to supplement natural forage or increase wildlife viewing opportunities.

\section{Commercially available attractants}

There are numerous commercially available attractants for wild pigs including food commodities, scents, calls, and decoys (see Table 1 and Supplemental Table 1). Commercial products are primarily marketed toward hunting and trapping activities, come in a variety of flavors and aromas, and are either standalone products or can be combined with other food commodities to make a more attractive attractant matrix.

Food commodities Commodities such as corn, wheat, barley, rice, soybeans, peanuts, and sorghum are commonly used to attract wild pigs. Traditionally, harvested grain has been used as the core ingredient in homemade attractant recipes, with corn the most popular in the USA (West et al. 2009; Hamrick et al. 2011; Williams et al. 2011). Corn is relatively low in cost, extremely abundant, can be purchased by bag or in bulk, and is generally preferred by wild pigs, making it the standard for grain attractants (Mayer and Brisbin 2009; NASS 2016; NFSDMP 2016). Wheat is used similarly in other countries around the globe where it is a more commonly grown grain (Saunders et al. 1993; Wishart 2015). Widespread availability and low cost are often driving factors behind use of food commodities as attractants. There also might be regional differences in palatability by wild pigs making the best attractant regionally dependent (Mayer and Brisbin 2009).

Field trials in Georgia and Texas, USA, demonstrated no difference between use of soured or dry corn in both time to visit and duration of feeding bout (Fig. 1; Wyckoff et al. 2006; Williams et al. 2011). Conversely, it was determined that wild pigs in Great Smoky Mountain National Park preferred fermented corn mash to a wide array of alternative scents and flavors (e.g., spoiled milk, beer, walnut extract, and strawberry flavoring) with minimal visitation by non-target species (Wathen et al. 1988). Interestingly, visitation to control sites (raked ground with no attractant) exceeded treatment sites, suggesting that the scent of recently turned soil and visual cue of exposed soil attracted wild pigs (Wathen et al. 1988).

Inquiries into the most commonly used attractants by professional USDA APHIS WS pig trappers revealed 82 and $67 \%(n=40)$ routinely used dry or soured corn, respectively (unpublished data). Soured corn is very popular, with hundreds of bait recipes available online. In general, the recipe for soured corn calls for a barrel or trash can full of wholekernel corn then filled with water and allowed sufficient time to ferment (Fig. 1). Commonly used additives to speed fermentation and enhance scent and flavor include sugar, molasses, beer, jello or gelatin powder, and yeast (Mayer and Brisbin 2009; Reidy et al. 2011; NFSDMP 2016). This process results in pungent odors, which are thought to be attractive to wild pigs, and in some instances, may reduce nontarget visitation (West et al. 2009).

Although delivery of grains directly on the ground is undoubtedly the most common technique for attracting wild pigs, a variety of other strategies exist. For example, roll pipes or hog pipes are tethered and capped PVC pipes with holes drilled in them so that corn or other grain-based commodities are gradually dispensed through pre-drilled holes when they are moved around by wild pigs, therefore prolonging delivery and consumption (Fig. 1; West et al. 2009). Corn holes or post holes are small diameter holes $(\approx 25 \mathrm{~cm}$ in circumference and $\approx 35 \mathrm{~cm}$ depth) dug in the ground, filled with attractants, and often used to locate wild pigs for further baiting efforts or to prolong or increase frequency of repeated visitation (West et al. 2009). Elevated spin cast feeders with programmed timers offer consistent attractant disbursement, and help establish a predictable schedule of visitation. Limiting consumption, slowing access, and standardizing delivery are strategies used to increase attractant efficiency and the duration of visitation, and to reduce costs.

Commodities such as wheat, sorghum, barley, and rice are used less frequently for attracting wild pigs in the USA; however, these crops are readily damaged by wild pigs (Seward et al. 2004; Mayer and Brisbin 2009). Whole shelled wheat and fermented wheat are commonly used in Australia for attracting wild pigs (Saunders et al. 1993; Wishart 2015). Milo (Thespesia populnea), a type of grain sorghum, has been used successfully to increase visitation to other attractants while increasing duration of attractant availability as kernels are quite small and are difficult to remove completely (McIlroy et al. 1993; Saunders 1993; NFSDMP 2016).

When available, fermented soybeans $($ G. $\max$ ) are often a favorite attractant (West et al. 2009). Legumes including chufas (Cyperus esculentus) and peanuts are highly desired regionally and sought by wild pigs (W. Gaston and M. Ondovchik, USDA APHIS WS, personal communication). Further, peanut paste and peanut waste are often effective as attractants for wild pigs when available (West et al. 2009; NFSDMP 2016; Snow et al. 2016b). After mechanical 
separation, peanut waste, consisting of hulls, skins, leaves, stems, and residual amounts of nuts, is highly odiferous and can serve as an excellent attractant (B. Ferris, USDA APHIS WS, personal communication).

Various livestock supplements have also been tried with reasonable success. Cattle supplements such as range cubes or cow cakes (e.g., Lightning 20 Cubed Nutrition Concentrate, AC Nutrition Services, Winters, TX, USA) have been used as an attractant for wild pigs (R. Jones, USDA APHIS WS, personal communication). Dry pig Krave ${ }^{\circledR}$ (Nutriad International, Dendermonde, Belgium), a dietary supplement used to improve palatability of feeds in domestic pig production, has proven effective when added to wholekernel corn (NFSDMP 2016). Less common commoditybased attractants include spoiled fruits and vegetables, whole or preserved fish and fish oil, dry dog food, molasses, cut meat, soured chicken mash, and carrion (Mayer and Brisbin 2009; West et al. 2009; Hamrick et al. 2011; McPeake et al. 2015).

Commercially produced attractants Generally, there are three major categories of commercially produced attractants: solid, liquid, and aerosol. Solid attractants come powdered, granular, as solid blocks, or in paste form; liquid attractant formulations range in viscosities and concentrations. Aerosol or scent attractants mimic foods or conspecifics, and may come in a range of flavors. Scent attractants are generally a liquid by-product and, in states where baiting is legal, are used in conjunction with other items to attract wild pigs. Scent attractants targeting conspecifics mainly consist of variants of dominant male and female-in-estrus pheromones.

There are several common flavors used in commercially available attractants including berries, molasses, corn, apple, grape, and various nuts such as acorn, peanut, and peanut butter. Sour-tasting attractants are also common including sour corn, sour apple, and sour acorn (Fig. 1). Other less common flavors include pastries, smelly cheese, carrion, vanilla, cinnamon, fresh cut hay, and ice cream. Many products do not explicitly disclose a specific flavor, but careful exploration of the label, description, and recommended use can usually determine if the product is sweet or sour.

Solid attractants are most often produced as granules or pellets though some products are solid cubes or a paste (see Supplemental Table 1). These attractants act as a food source, but some mimic conspecific pheromones. While some granular attractants are marketed as standalone, they are often added to grains or other commercially available products to make them more desirable. Some granular attractants are designed to expand in volume and become more odorous with addition of water and are recommended to be applied in corn holes or spread directly on the ground to leach into the soil. Some granular or pelletized products are designed to be mixed with corn and dispensed through spin-cast feeders or dispensed on the ground. Solid blocks similar to supplemental mineral blocks for livestock are intended to be buried just under the surface of the soil for wild pigs to seek out and consume. Concentrated pastes and deodorant-like sticks are available and contain highly concentrated conspecific scents. These are both highly odorous and are intended for use by rubbing or marking surfaces such as rocks, trees, or vegetation proximate to hunting or trapping sites.

Liquid attractants are available in small amounts $(30+\mathrm{ml})$ of highly concentrated conspecific scents and larger volumes (1-4 1) of food resource attractants. Liquid attractants are applied with applicators such as scent wicks, slow drip devices, spray bottles, or poured, smeared, or otherwise applied directly to vegetation at hunting or trapping sites. Liquid conspecific attractants are purported to attract large, dominant males and are mostly urine based and marketed in two general forms, female-in-estrus and dominant males. Female-in-estrus urine attractant targets the reproductive instinct in males while the dominant boar attractant targets an aggressive, territorial response in males.

Liquid food resource attractants come in a wide variety of flavors, concentrations, and viscosities. These attractants mimic a food resource and are generally applied directly on the ground, in corn holes, in existing wallows, or on tree stumps, logs, or vegetation. Many of these products are packaged and designed to be punctured and hung from a tree, allowing a low-viscosity liquid to slowly drip out. Liquid food resource attractants can also be mixed with commodity-based attractants or other commercially available solid attractants to enhance taste and smell.

Aerosol attractants are liquid scent particles under pressure and released as a fine spray. Commercially produced aerosols, commonly referred to as scent foggers, are intended to saturate an area with conspecific or food resource scents. Most commercially available aerosols can be sprayed in small quantities or emptied all at once and are to be dispersed in a light wind to attract animals from long distances. Conspecific aerosol attractants are available in dominant male and female-in-estrus scents while food resource aerosol attractants are offered in several flavors.

Many companies producing attractants for wild pigs tout special formulations, propriety ingredients, trade secrets, and quality testing and research to reinforce their product as an exceptional choice in a market with many options. Anecdotally from online consumer reviews, all commercial attractants seem to show some utility in attracting wild pigs; however, success of these commercial products seems to vary with geography, duration of use, and how the product is applied. Commercial attractants provide many options to lure wild pigs, but rigorous studies reporting comparable efficacy are lacking.

Auditory attractants or calls are widely available. Manual calls generally utilize a reed and/or tube while electronic 
calling devices offer an array of amplified pig sounds. Additionally, there are smartphone applications that transmit male and female pig sounds to an external speaker via cable or bluetooth technology. Calls are commonly used in hunting various species of game animals in the USA though are not widespread for attracting wild pigs.

Use of visual attractants or decoys to attract wild pigs is not common practice. While wild pigs are not generally territorial and do not actively defend an exclusive area, they do have mating and dominance behaviors similar to wild ungulates, which could make them susceptible to decoy use in hunting scenarios (Mayer and Brisbin 2009). Live pigs (domestic or wild) in cages, serving as decoys, have been used with some success in attracting and capturing wild pigs (McIlroy and Gifford 2005; K. VerCauteren, USDA APHIS WS, personal communication).

Several extensive research efforts focusing on attractants for wild pigs have been conducted over the last few decades (Supplemental Tables 2 and 3) (Wathen et al. 1988; Campbell and Long 2008; Snow et al. 2016b); however, conclusive results defining the most effective attractants are lacking (Wathen et al. 1988; Mitchell 1998; Hartin et al. 2007; Campbell and Long 2008). Researchers in Spain have been working toward developing baits (consisting of grainy piglet feed, sodium chloride, sacarose, and cinnamon-truffle powder) and a deployment strategy for vaccinating susceptible young wild piglets against bovine tuberculosis (Ballesteros et al. 2011). In Australia, researchers delivered antifertility agents to wild pigs, and corn was the preferred attractant (Supplemental Table 3) (Bengsen et al. 2011). Australian researchers also demonstrated no preference among captive and free-ranging wild pigs for meat, grain, and fruit-based attractants as well as several other candidate attractants (Elsworth et al. 2004).

\section{Non-target species impacts}

Use of attractants for oral delivery of toxicants or bioactives such as vaccines and oral contraceptives to free-ranging wildlife for population control is receiving increasing attention; however, efficacy and feasibility of delivery systems should be determined before operational activities are implemented (Campbell et al. 2011; Campbell et al. 2013; Ferretti et al. 2014; Snow et al. 2016b). Challenges associated with these efforts are compounded when delivery to non-target species is unacceptable or problematic, hence the need for wild pigspecific delivery devices. Competitive foraging strategies within a wild pig sounder requires a delivery option that enables all pigs to consume adequate levels of pharmaceuticallaced foods (Lavelle et al. Submitted). Delivery devices that target the rooting abilities of wild pigs and incorporate a resistance device show promise and reduce potential for access by non-target species (Long et al. 2010; Campbell et al. 2011; Ferretti et al. 2014; Snow et al. 2017).

Documented non-target visitation and consumption of baits specific to wild pig attractants in the USA and AU are detailed in Supplemental Tables 2 and 3, respectively. Researchers evaluated 11 candidate attractants for wild pigs in Texas, USA, and found that apple, berry, and caramel scents performed well in attracting wild pigs with strawberry scent, the best pig-specific attractant (Campbell and Long 2008). In Queensland, AU, the addition of creosote to candidate attractants reduced consumption by non-target species (Elsworth et al. 2004); however, black bears (Ursus americanus) in TN, USA, visited creosote at rates similar to wild pigs (Wathen et al. 1988). Results from a different study that focused on attractants for delivery of bioactives to bears and wild pigs reported inconclusive preferences among wild pigs, although visitation and consumption rates by both species were high for all candidate attractants (e.g., $\geq 80 \%$ ) (Kavanaugh and Linhart 2000). Two non-target species, raccoons and collared peccary, were documented not visiting sites with strawberry scent; however, apple scent appeared to attract raccoons (Campbell and Long 2008). Strawberry flavoring has also provided reliable attraction to wild pigs without drawing raccoons; however, deer were attracted to strawberry flavoring (Campbell and Long 2009).

Adequate prebaiting is essential for success, and at least 36 days are needed to concentrate and accustom wild pigs to new food sources (Linhart et al. 1993; Campbell et al. 2011; Twigg et al. 2005). Further, it is recommended that bait stations be established and supplied for 3-7 days prior to incorporating any bioactive agent (Linhart et al. 1993). Prebaiting in excess of 14 days, however, does increase the potential for visitation and consumption of attractants by raccoons (Campbell et al. 2013). We found that six nights, with daily resupply, provided enough time to establish routine visitation prior to introducing anything novel such as unfamiliar foods or an attractant delivery station (Snow et al. 2016b).

To improve success in maximizing visitation by wild pigs while minimizing visitation by non-target species, one must first identify potential non-target species and determine which attractants may appeal to them. Although the most common non-target species of concern are going to be wildlife, when delivering bioactives, there is also the concern of exposure to and consumption by domestic animals and even humans. As herbivores, deer will be drawn to vegetation, grains, and/or mast, while omnivores like bears and raccoons may be drawn to almost anything. In situations where bears are present and locating attractants intended for wild pigs, relocating to another site may be the best option to minimize potential risk of visitation by bears. Consumption or removal of attractants by non-targets also reduces the likelihood of that target species to consume pharmaceuticals, thus increasing costs and reducing efficiency (Fleming et al. 2000). Concerns over potential non- 
target impacts cannot be secondary to the primary objective when considering potentially harmful substances such as toxicants (O'Brien 1986).

Species specificity of wildlife management activities is important for efficiency and efficacy; thus, details such as characteristics of attractants, acuity of senses, and the spatiotemporal distribution of the relevant species should be determined and considered early in strategizing (Humphrys and Lapidge 2008). Further, Bengsen et al. (2010) states the speciesspecific objective concisely: "Most efforts to develop targetspecific pest control tools have sought to exploit morphological, behavioural, sensory, or physiological differences between pest and non-target species, in order to reduce adverse non-target impacts without inhibiting the efficacy of control." By evaluating and comparing feeding behaviors of target and non-target species, one can focus on baiting strategies that may narrow delivery to the target species. For example, burying attractants intended for consumption by pigs improves potential for consumption by animals that employ rooting in normal foraging activities, though it needs to be realized that fossorial species may then be impacted (Brooks et al. 1990; Bengsen et al. 2010). Incorporating temporal aspects of feeding behaviors of target species also improves the potential to reduce exposure of attractants to non-target species. For example, providing attractants only during nighttime hours will minimize consumption by diurnal feeders and provide access to nocturnal and crepuscular feeders like pigs (Bengsen et al. 2010). In situations where potential risk of delivering pharmaceutical-laced attractants to smaller non-target species is unavoidable, but which needs to be minimized, it has been suggested that a small quantity of non-laced decoy attractant be made readily available to satisfy their demands and minimize potential for consumption of laced attractants (Bengsen et al. 2010).

\section{Conclusions}

As opportunistic generalist feeders, wild pigs have a varied diet and adapt to what is available. There, foraging strategy creates unique challenges when attempting to entice pigs to a specific location, given that there are almost always naturally occurring alternative foods available. For example, soft mast such as palmetto berries (Serenoa repens) are preferred by wild pigs, and during periods when they are plentiful, success in using whole-kernel corn as an attractant drops dramatically (Fletcher et al. 1990). Understanding availability of natural food resources enables one to realize potential challenges relative to a particular baiting strategy, and may lead one to either attempt to provide something more enticing, delay until the availability of natural resources wanes, or adjust locations by targeting alternate habitat, travel corridors, water sources, bedding areas. Further, combining preferred foods with a scent attractant or visual lure may provide additional incentive that could help to outcompete available natural foods.

Strategies implemented when using attractants play a very important role in the overall success of management actions. This review demonstrates that the preferences, behaviors, and motivation among wild pigs vary considerably by region, season, age class, sex, and even time of day. Contributing factors such as level and method of persecution, availability of natural forage, competition within and among species, and weather all play into this variability to some extent. Further, this variability exacerbates challenges associated with identifying a superior attractant for enticing wild pigs. As such, it behooves individuals targeting wild pigs to first determine available natural forages and anthropocentric resources available that potentially may act as competition, and second, determine locations that will increase likelihood of wild pigs encountering introduced attractants. The potential for attractant success should improve by locating attractant sites near agricultural field perimeters that are being visited. Mimicking or even using foods already being sought by wild pigs may also improve potential for success. During attractant site selection, a key factor to success is identifying evidence of recent wild pig activity. Additionally is the evaluation of the site for evidence of non-target activity to minimize potential for non-target vistation, evaluating a site for evidence of non-target activity is recommended.

Commonly used attractants are usually those that are readily available, affordable, and easy to deliver. Whole-kernel corn is the most reliably effective attractant across the USA and throughout much of wild pig range; however, alternatives are needed and comparative evaluations of these and other candidate attractants are warranted. Further, knowledge of effective alternatives to corn can best be gained when alternatives are compared directly with corn, and thus this is in need of future research. While dry corn and soured corn are commonly used with relatively predictable success, the relative efficacy of fermented corn mash (Fig. 1; alone and with the addition of spoiled milk, strawberry, or beer) should be investigated as it has been touted as superior. Flavor additives including sweeteners and substances with umami and cheesy characteristics also deserve further consideration for improving the efficacy of base attractants. Commercially available products such as Hog Mate ${ }^{\mathrm{TM}} /$ Boarmate $^{\mathrm{TM}}$, Carasweet (Agricon Products, Maryborough, Queensland, AU), fish oil, and sow-in-estrus scents should be evaluated as general scent attractants. Fruity scents such as grape and strawberry should be considered along with others including synthetic fermented eggs, blood and bone meal, and meat as they have been recommended by others as appealing to wild pigs and not to other species. Combined use of attractants for wild pigs and deterrents for non-target species is also worth considering.

A primary goal of this review was to identify candidate attractants that are highly effective in enticing wild pigs while having minimal appeal to non-target species. In regards to 
attractants that effectively entice wild pigs while avoiding being considered "bait" under regulatory restrictions, there are few that clearly demonstrate potential for success. The most simple and inexpensive is freshly turned soil, which in some evaluations outperformed all other attractants. Substances that emit a strong petrochemical odor including diesel and motor oil smells have been reported attractive though results are highly variable and unsubstantiated. Further, creosoteimpregnated fence posts and telephone poles have long been considered attractive to wild pigs, though they deserve careful evaluation as a standalone attractant. As these final petrochemical and creosote substances pose potential personal health and environmental risks, their use is not suggested herein.

Delivery of food attractants should be considered and tailored to the predicted level of non-target competition and strategies such as burying or covering attractants or timing the delivery around periods of non-target activity may improve target specificity. In situations where nontarget exposure is unacceptable, pig-specific bait stations should be considered. Abiding by local rules and regulations regarding use of attractants is also essential. Unnecessarily congregating wildlife poses increased risks for disease transmission and, once they become available, unintended exposure to toxicants and pharmaceuticals. Thus, each situation and potential risks should be evaluated prior to initiating management actions.

\section{References}

Adams CE (2016) Urban wildlife management. CRC press, Boca Raton Algers B (1993) Nursing in pigs: communicating needs and distributing resources. J Anim Sci 71:2826-2831

Anderson A, Slootmaker C, Harper E, Holderieath J, Shwiff SA (2016) Economic estimates of feral swine damage and control in 11 US states. Crop Prot 89:89-94

Atwill ER, Sweitzer RA, Pereira M, Gardner IA, Van Vuren D, Boyce WM (1997) Prevalence of and associated risk factors for shedding Cryptosporidium parvum oocysts and Giardia cysts within feral pig populations in California. Appl Env Microbiol 63:3946-3949

Baber DW, Coblentz BE (1986) Density, home range, habitat use, and reproduction in feral pigs on Santa Catalina Island. J Mamm 67: 512-525

Bacchetta R, Mantecca P, Lattuada L, Quaglia F, Vailati G, Apollonio M (2007) The carpal gland in wild swine: functional evaluations Italian. J Zool 74:7-12

Bachmanov AA, Beauchamp GK (2007) Taste receptor genes. Annu Rev Nutr 27:389

Ballari SA, Barrios-García MN (2014) A review of wild boar Sus scrofa diet and factors affecting food selection in native and introduced ranges. Mammal Rev 44:124-134

Ballesteros C, Vicente J, Carrasco-García R, Mateo R, de la Fuente J, Gortázar C (2011) Specificity and success oral-bait delivery to European wild boar in Mediterranean woodland habitats. Eur J Wildl Res 57:749-757
Baubet E, Ropert-Coudert Y, Brandt S (2003) Seasonal and annual variations in earthworm consumption by wild boar (Sus scrofa scrofa L.) Wildl Res 30:179-186

Bengsen AJ, Leung LK-P, Lapidge SJ, Gordon IJ (2010) Developing Target-specific baiting methods for feral pigs in an omnivore-rich community. Vert Pest Conf. University of California, Davis, p 53

Bengsen AJ, Leung LK-P, Lapidge SJ, Gordon IJ (2011) Targetspecificity of feral pig baits under different conditions in a tropical rainforest. Wildl Res 38:370-379

Bevins SN, Pedersen K, Lutman MW, Gidlewski T, Deliberto TJ (2014) Consequences associated with the recent range expansion of nonnative feral swine. BioSci 64:291-299

Boitani L, Mattei L, Nonis D, Corsi F (1994) Spatial and activity patterns of wild boars in Tuscany, Italy. J Mammal 75:600-612

Bradley RM (1971) Tongue topography. In: Taste. Springer, Berlin, DE

Breer H, Fleischer J, Strotmann J (2006) The sense of smell: multiple olfactory subsystems. Cell Mol Life Sci 63:1465-1475

Brooks R, Pearson A (1986) Steroid hormone pathways in the pig, with special emphasis on boar odor: a review. J Anim Sci 62:632-645

Brooks JE, Ahmad E, Hussain I, Munir S, Khan MH, Asif MM (1990) Field evaluation of candidate toxicants, baits, and bait delivery systems for control of wild boar. Tech Rep 23. Islamabad, PK

Calenge C, Maillard D, Fournier P, Fouque C (2004) Efficiency of spreading maize in the garrigues to reduce wild boar (Sus scrofa) damage to Mediterranean vineyards. Eur J Wildl Res 50:112-120

Caley P (1997) Movements, activity patterns and habitat use of feral pigs (Sus scrofa) in a tropical habitat. Wildl Res 24:77-87

Campbell TA, Long DB (2007) Species-specific visitation and removal of baits for delivery of pharmaceuticals to feral swine. J Wildl Dis 43: 485-491

Campbell TA, Long DB (2008) Mammalian visitation to candidate feral swine attractants. J Wildl Manag 72:305-309

Campbell TA, Long DB (2009) Strawberry-flavored baits for pharmaceutical delivery to feral swine. J Wildl Manag 73:615-619

Campbell TA, Lapidge SJ, Long DB (2006) Using baits to deliver pharmaceuticals to feral swine in southern Texas. Wildl Soc Bull 34: 1184-1189

Campbell TA, Long DB, Leland BR (2010) Feral swine behavior relative to aerial gunning in southern Texas. J Wildl Manag 74:337-341

Campbell TA, Long DB, Massei G (2011) Efficacy of the boar-operatedsystem to deliver baits to feral swine. Prev Vet Med 98:243-249

Campbell TA, Foster JA, Bodenchuk MJ, Eisemann JD, Staples L, Lapidge SJ (2013) Effectiveness and target-specificity of a novel design of food dispenser to deliver a toxin to feral swine in the United States International. J Pest Manage 59:197-204

Challies CN (1975) Feral pigs (Sus scrofa) on Auckland Island: status, and effects on vegetation and nesting sea birds. N Z J Zool 2:479490

Chamorro C, De Paz P, Fernández J, Anel L (1993) Fungiform papillae of the pig and the wild boar analyzed by scanning electron microscopy. Scanning Microsc 7:313-320

Choquenot D, Kilgour RJ, Lukins BS (1993) An evaluation of feral pig trapping. Wildl Res 20:15-21

Claus R, Hoppen H, Karg H (1981) The secret of truffles: a steroidal pheromone? Experientia 37:1178-1179

Comer CE, Mayer JJ (2009) Wild pig reproductive biology. In: Mayer JJ, Brisbin IL Jr (eds) Wild pigs: biology, damage, control techniques, and management. Savannah River National Laboratory, Aiken, pp $51-75$

Corona R, Lévy F (2015) Chemical olfactory signals and parenthood in mammals. Horm Behav 68:77-90

Croney C, Adams K, Washington C, Stricklin W (2003) A note on visual, olfactory and spatial cue use in foraging behavior of pigs: indirectly assessing cognitive abilities. Appl Anim Behav Sci 83:303-308

Cuddihy LW, Stone CP (1990) Alteration of native Hawaiian vegetation. University of Hawaii Cooperative National Park Study Unit 
da Silva EC, de Jager N, Burgos-Paz W, Reverter A, Perez-Enciso M, Roura E (2014) Characterization of the porcine nutrient and taste receptor gene repertoire in domestic and wild populations across the globe. BMC Genomics 15:1

Danilova V, Roberts T, Hellekant G (1999) Responses of single taste fibers and whole chorda tympani and glossopharyngeal nerve in the domestic pig, Sus scrofa. Chem Senses 24:301-316

Deligeorgis SG, Karalis K, Kanzouros G (2006) The influence of drinker location and colour on drinking behaviour and water intake of newborn pigs under hot environments. Appl Anim Behav Sci 96:233244

Dickson JG, Mayer JJ, Dickson JD (2001) Wildlife of southern forests: habitat and management surrey. Hancock House Publishers, Blaine

Ditchkoff SS, Mayer JJ (2009) Wild pig food habits. In: Mayer JJ, Brisbin IL Jr (eds) Wild pigs: biology, damage, control techniques, and management. Savannah River National Laboratory, Aiken, pp $105-143$

Dorries KM, Adkins-Regan E, Halpern BP (1991) Sex difference in olfactory sensitivity to the boar chemosignal, androstenone, in the domestic pig. Anim Behav 42:403-411

Dorries KM, Adkins-Regan E, Halpern BP (1995) Olfactory sensitivity to the pheromone, androstenone, is sexually dimorphic in the pig. Physiol Behav 57:255-259

Dyce KM, Sack W, Wensing C (1987) Textbook of veterinary anatomy. Elsevier Health Sciences

Eguchi Y, Tanida H, Tanaka T, Yoshimoto T (1997) Color discrimination in wild boars. J Ethol 15:1-7

Elsey RM, Mouton EC Jr, Kinler N (2012) Effects of feral swine (Sus scrofa) on alligator (Alligator mississippiensis) nests in Louisiana. Southeast Nat 11:205-218

Elsworth P, Mitchell J, Parker R (2004) Evaluation of attractants and toxins for improved target specificity in the control of feral pigs. Report to the National Feral Animal Control Program. Department of Natural Resources and Mines, Inglewood

Estes RD, Cumming DH, Hearn GW (1982) New facial glands in domestic pig and warthog. J Mammal 63:618-624

Farnesi R, Vagnetti D, Santarella B, Tei S (1999) Morphological and ultrastructural study of carpal organ in adult female wild swine. Anat Histol Embryol 28:31-38

Fernández-Llario $\mathrm{P}$ (2005) The sexual function of wallowing in male wild boar (Sus scrofa). J Ethol 23:9-14

Ferretti F, Sforzi A, Coats J, Massei G (2014) The BOSTM as a speciesspecific method to deliver baits to wild boar in a Mediterranean area. Euro J Wildl Res 60:555-558

Fleming PJ, Choquenot D, Mason RJ (2000) Aerial baiting of feral pigs (Sus scrofa) for the control of exotic disease in the semi-arid rangelands of New South Wales. Wildl Res 27:531-537

Fletcher WO, Creekmore TE, Smith MS, Nettles VF (1990) A field trial to determine the feasibility of delivering oral vaccines to wild swine. J Wildl Dis 26:502-510

Fraser D (1980) A review of the behavioural mechanism of milk ejection of the domestic pig. Appl Anim Ethol 6:247-255

Gabor TM, Hellgren EC, Silvy NJ (1997) Renal morphology of sympatric suiforms: implications for competition. J Mammal 78:10891095

Gabor TM, Hellgren EC, Bussche RA, Silvy NJ (1999) Demography, sociospatial behaviour and genetics of feral pigs (Sus scrofa) in a semi-arid environment. J Zool 247:311-322

Garrick LD, Lang JW, Herzog HA Jr (1978) Social signals of adult American alligators. Bull Am Mus Nat His 160:157-192

Gieling ET, Nordquist RE, van der Staay FJ (2011) Assessing learning and memory in pigs. Anim Cognit 14:151-173

Giménez-Anaya A, Herrero J, Rosell C, Couto S, García-Serrano A (2008) Food habits of wild boars (Sus scrofa) in a Mediterranean coastal wetland. Wetlands 28:197-203
Glaser D, Wanner M, Tinti J, Nofre C (2000) Gustatory responses of pigs to various natural and artificial compounds known to be sweet in man. Food Chem 68:375-385

Gortázar C et al (2008) Bovine tuberculosis in Donana Biosphere Reserve: the role of wild ungulates as disease reservoirs in the last Iberian lynx strongholds. PLoS One e2776:3

Graves H (1984) Behavior and ecology of wild and feral swine (Sus scrofa). J Anim Sci 58:482-492

Guntherschulze vJ (1979) Studien zur Kenntnis der Regio olfactoria von Wild-und Hausschwein (Sus scrofa scrofa L. 1768 und Sus scrofaf. domestica). Zoologischer Anzeiger

Hampton J, Pluske JR, Spencer PB (2004) A preliminary genetic study of the social biology of feral pigs in south-western Australia and the implications for management. Wildl Res 31:375-381

Hamrick B, Campbell T, Higginbotham B, Lapidge S (2011) Managing an invasion: effective measures to control wild pigs, Mississippi State University Extension Service and Alabama Cooperative Extension Service

Hartin RE, Ryan MR, Campbell TA (2007) Distribution and disease prevalence of feral hogs in Missouri. Human-Wildl Conflicts 1: 186-191

Heffner RS, Heffner HE (1990) Hearing in domestic pigs (Sus scrofa) and goats (Capra hircus). Hear Res 48:231-240

Heise-Pavlov S, Heise-Pavlov P, Bradley A (2005) Carpal glands in feral pigs (Sus domesticus) in tropical lowland rainforest in north-east Queensland, Australia. J Zool 266:73-80

Held S, Cooper JJ, Mendl MT (2009) Advances in the study of cognition, behavioural priorities and emotions. In: Marchant-Forde JN (ed) The welfare of pigs, Springer pp 47-94

Hellekant G, Danilova V (1996) Species differences toward sweeteners. Food Chem 56:323-328

Hellekant G, Danilova V (1999) Taste in domestic pig, Sus scrofa. J Anim Physiol Anim Nutr 82:8-24

Henry VG, Conley RH (1972) Fall foods of European wild hogs in the southern Appalachians. J Wildl Manag 36:854-860

Herrero J, García-Serrano A, Couto S, Ortuño VM, García-González R (2006) Diet of wild boar Sus scrofa L. and crop damage in an intensive agroecosystem. Eur J Wildl Res 52:245-250

Hraste A, Stojković R (1995) Histomorphologic and histochemical characteristics of carpal glands (Glandulae Carpeae) in domestic swine (Sus scrofa domesticus) and wild swine (Sus scrofa ferus). Anat Histol Embryol 24:209-211

Humphrys S, Lapidge SJ (2008) Delivering and registering speciestailored oral antifertility products: a review. Wildl Res 35:578-585

Hutson G, Argent M, Dickenson L, Luxford B (1992) Influence of parity and time since parturition on responsiveness of sows to a piglet distress call. Appl Anim Behav Sci 34:303-313

Janeau G, Spitz F (1990) Dispersal in relation to density in wild boar. In: Transactions of the 19th IUGB Congress, Trondheim, Norway pp $59-62$

Jensen P (1986) Observations on the maternal behaviour of free-ranging domestic pigs. Appl Anim Behav Sci 16:131-142

Kare MR, Pond W, Campbell J (1965) Observations on the taste reactions in pigs. Anim Behav 13:265-269

Kavanaugh D, Linhart S (2000) A modified bait for oral delivery of biological agents to raccoons and feral swine. J Wildl Dis 36:86-91

Kennedy J, Baldwin B (1972) Taste preferences in pigs for nutritive and non-nutritive sweet solutions. Anim Behav 20:706-718

Kittawornrat A, Zimmerman JJ (2011) Toward a better understanding of pig behavior and pig welfare. Anim Health Res Rev 12:25-32

Koba Y, Tanida H (2001) How do miniature pigs discriminate between people?: discrimination between people wearing coveralls of the same colour. Appl Anim Behav Sci 73:45-58

Kornum BR, Knudsen GM (2011) Cognitive testing of pigs (Sus scrofa) in translational biobehavioral research. Neurosci Biobehav Rev 35: $437-451$ 
Kouwenberg A-L, Walsh CJ, Morgan BE, Martin GM (2009) Episodiclike memory in crossbred Yucatan minipigs (Sus scrofa). Appl Anim Behav Sci 117:165-172

Kurz JC, Marchinton RL (1972) Radiotelemetry studies of feral hogs in South Carolina. J Wildl Manag 36:1240-1248

Linhart S, Kappeler A, Windberg LA (1993) Review of baits and bait delivery systems for free-ranging carnivores and ungulates. In: Kreeger T (ed) Contraception in wildlife managment, Denver, CO, USA p 272

Long DB, Campbell TA, Massei G (2010) Evaluation of feral swinespecific feeder systems. Rangelands 32:8-13

Mapston M (2007) Feral hogs in Texas. Texas Cooperative Extension

Mayer JJ (2009) Wild pig behavior. In: Mayer JJ, Brisbin IL (eds) Wild pigs biology, damage, control, techniques, and management. Savanna River National Laboratory, Aiken

Mayer J, Brisbin I (2009) Wild pigs: biology, damage, control techniques and management. Savannah River National Laboratory, Aiken

McIlroy J, Gifford E (1997) The 'Judas' pig technique: a method that could enhance control programmes against feral pigs, Sus scrofa. Wildl Res 24:483-491

McIlroy J, Gifford E (2005) Are oestrous feral pigs, Sus scrofa, useful as trapping lures? Wildl Res 32:605-608

McIlroy J, Gifford E, Forrester R (1993) Seasonal patterns in bait consumption by feral pigs (Sus Scrofa) in the hill country of southeastern Australia. Wildl Res 20:637-651

McLaughlin CL, Baile CA, Buckholtz LL, Freeman SK (1983) Preferred flavors and performance of weanling pigs. J Anim Sci 56:12871293

McLeman MA, Mendl M, Jones RB, White R, Wathes CM (2005) Discrimination of conspecifics by juvenile domestic pigs, Sus scrofa. Anim Behav 70:451-461

McPeake R, Hoy M, Fairhead JP (2015) Feral hog control in Arkansas. University of Arkansas Cooperative Extension

Meese G, Conner D, Baldwin B (1975) Ability of the pig to distinguish between conspecific urine samples using olfaction. Physiol Behav $15: 121-125$

Melrose D, Reed H, Patterson R (1971) Androgen steroids associated with boar odour as an aid to the detection of oestrus in pig artificial insemination. Br Vet J 127:497-502

Miller IJ, Reedy FE (1990) Variations in human taste bud density and taste intensity perception. Physiol Behav 47:1213-1219

Mitchell J (1998) The effectiveness of aerial baiting for control of feral pigs (Sus scrofa) in North Queensland. Wildl Res 25:297-303

Muir T, McEwen G (2007) Methods and strategies for managing feral hog damage in grain production areas in central Texas. Managing Vertebr Invasive Species, 32

Mykytowycz R (1977) Olfaction in relation to reproduction in domestic animals. In: Muller-Schwarze D, Mozell M (eds) Chemical signals in vertebrates. Plenum Press, New York, pp 207-224

NASS USDoANASS- (2016) Crop Production Historical Track Records

National Feral Swine Damage Management Program (2016) Feral swine management methods guide: strategies for the capture and removal of an invasive species

Neitz J, Jacobs GH (1989) Spectral sensitivity of cones in an ungulate. Vis Neurosci 2:97-100

Nelson SL, Sanregret JD (1997) Response of pigs to bitter-tasting compounds. Chem Senses 22:129-132

Nofre C, Glaser D, Tinti JM, Wanner M (2002) Gustatory responses of pigs to sixty compounds tasting sweet to humans. J Anim Physiol Aanim Nutr 86:90-96

O'Brien PH (1986) An approach to the design of target-specific vertebrate pest control systems. Vertebr Pest Conf 12:247-252

Pacioni G (1986) Truffle hunting in Italy. Bull Br Mycol Soc 20:50-51

Pimentel D, Zuniga R, Morrison D (2005) Update on the environmental and economic costs associated with alien-invasive species in the United States. Ecol Econ 52:273-288
Pine D, Gerdes G (1973) Wild pigs in Monterey County, California. Calif Fish Game 59:126-137

Rafferty KL, Herring SW, Marshall CD (2003) Biomechanics of the rostrum and the role of facial sutures. J Morphol 257:33-44

Reed H, Melrose D, Patterson R (1974) Androgen steroids as an aid to the detection of oestrus in pig artificial insemination. Br Vet J 130:6166

Reidy MM, Campbell TA, Hewitt DG (2011) A mark-recapture technique for monitoring feral swine populations. Rangel Ecol Manag 64:316-318

Roura E, Humphrey B, Tedó G, Ipharraguerre I (2008) Unfolding the codes of short-term feed appetence in farm and companion animals. A comparative oronasal nutrient sensing biology review. Can J Anim Sci 88:535-558

Roura E, Humphrey B, Klasing K, Swart M (2011) Is the pig a good umami sensing model for humans? A comparative taste receptor study. Flavour Frag J 26:282-285

Roura E, Koopmans S-J, Lallès J-P, Le Huerou-Luron I, de Jager N, Schuurman T, Val-Laillet D (2016) Critical review evaluating the pig as a model for human nutritional physiology. Nutr Res Rev 29: 60-90

Ruckel SW, Steele GW (1984) Alligator nesting ecology in two habitats in southern Georgia. In: Proc Annu Conf Southeast Assoc Fish and Wildl Agencies, pp 212-221

Saito M, Momose H, Mihira T (2011) Both environmental factors and countermeasures affect wild boar damage to rice paddies in Boso Peninsula, Japan. Crop Prot 30:1048-1054

Saito M, Koike F, Momose H, Mihira T, Uematsu S, Ohtani T, Sekiyama $\mathrm{K}$ (2012) Forecasting the range expansion of a recolonising wild boar Sus scrofa population. Wildl Biol 18:383-392

Saunders G (1993) Observations on the effectiveness of shooting feral pigs from helicopters. Wildl Res 20:771-776

Saunders G, Bryant H (1988) The evaluation of a feral pig eradication program during a simulated exotic disease outbreak. Wildl Res 15: $73-81$

Saunders G, Kay B, Nicol H (1993) Factors affecting bait uptake and trapping success for feral pigs (Sus scrofa) in Kosciusko National Park. Wildl Res 20:653-665

Schlageter A, Haag-Wackernagel D (2012) A gustatory repellent for protection of agricultural land from wild boar damage: an investigation on effectiveness. J Agri Sci 4:61

Schley L, Roper TJ (2003) Diet of wild boar Sus scrofa in Western Europe, with particular reference to consumption of agricultural crops. Mamm Rev 33:43-56

Seward NW, VerCauteren KC, Witmer GW, Engeman RM (2004) Feral swine impacts on agriculture and the environment. Sheep Goat Res J $12: 35-40$

Singer FJ (1981) Wild pig populations in the national parks. Env Manag 5:263-270

Snow NP, Jarzyna MA, VerCauteren KC (2016a) Interpreting and predicting the spread of invasive wild pigs. J Appl Ecol. https:// doi.org/10.1111/1365-2664.12866

Snow NP et al (2016b) Bait preference of free-ranging feral swine for delivery of a novel toxicant. PLoS One 11:e0146712

Snow NP, Lavelle MJ, Halseth JM, Blass CR, Foster JA, VerCauteren KC (2017) Development of a species-specific bait station for delivering toxic bait to invasive wild pigs. Wildl Soc Bull. Submitted

Spencer PB, Hampton JO (2005) Illegal translocation and genetic structure of feral pigs in Western Australia. J Wildl Manag 69:377-384

Sweeney JR, Sweeney JM, Sweeney SW (2003) Feral hog Sus scrofa. In: Feldhamer FA, Thompson BC, Chapman JA (eds) Wild mammals of North America. Johns Hopkins University Press, Baltimore

Sweitzer RA, Van Vuren DH (2002) Rooting and foraging effects of wild pigs on tree regeneration and acorn survival in California's oak woodland ecosystems. USDA Forest Service Gen Tech Rep PSWGTR-184 
Tanida H, Senda K, Suzuki S, Tanaka T, Yoshimoto T (1991) Color discrimination in weanling pigs. Anim Sci and Tech 62:1029-1034

Taylor RB, Hellgren EC (1997) Diet of feral hogs in the western South Texas Plains. Southwest Nat 42:33-39

Thomson C, Challies C (1988) Diet of feral pigs in the podocarp-tawa forests of the Urewera Ranges New Zealand. J Ecol 11:73-78

Tinti J, Glaser D, Wanner M, Nofre C (2000) Comparison of gustatory responses to amino acids in pigs and in humans. LWT-Food Sci Tech 33:578-583

Twigg LE, Lowe T, Martin G, Everett M (2005) Feral pigs in northwestern Australia: basic biology, bait consumption, and the efficacy of 1080 baits. Wildl Res 32:281-296

Wathen G, Thomas J, Farmer J (1988) European wild hog bait enhancement study. Final report. Res Manage Rep USDI National Park Service, Atlanta

Watson L (2004) WHOLE HOG. Smithsonian, Washington, DC

Weary DM, Fraser D (1995) Calling by domestic piglets: reliable signals of need? Anim Behav 50:1047-1055

Weary DM, Braithwaite LA, Fraser D (1998) Vocal response to pain in piglets. Appl Anim Behav Sci 56:161-172

West BC, Cooper AL, Armstrong JB (2009) Managing wild pigs: a technical guide vol 1. vol 55. Jack H. Berryman Institute, Department of Wildland Resources Utah State University Logan, UT, USA
Whittemore C, Fraser D (1974) The nursing and suckling behaviour of pigs. II. Vocalization of the sow in relation to suckling behaviour and milk ejection. Br Vet J 130:346-356

Williams BL, Holtfreter RW, Ditchkoff SS, Grand JB (2011) Efficiency of time-lapse intervals and simple baits for camera surveys of wild pigs. J Wildl Manag 75:655-659

Wishart J (2015) Feral pigs: a field guide to poison baiting PestSmart Toolkit publication Invasive Animals Cooperative Research Centre, Canberra, ACT ISBN:978-971

Witmer GW, Snow NP, Moulton RS (2014) Responses by wild house mice (Mus musculus) to various stimuli in a novel environment. Appl Anim Behav Sci 159:99-106

Wood GW, Barrett RH (1979) Status of wild pigs in the United States. Wildl Soc Bull 7:237-246

Wood-Gush D, Vestergaard K (1991) The seeking of novelty and its relation to play. Anim Behav 42:599-606

Wyckoff AC, Henke SE, Campbell T, VerCauteren KC (2006) Is trapping success of feral hogs dependent upon weather conditions? Vertebr Pest Conf 22:370-372 